\title{
Nuclear functions and subcellular trafficking mechanisms of the epidermal growth factor receptor family
}

\author{
Ying-Nai Wang ${ }^{1,2}$ and Mien-Chie Hung ${ }^{1,2^{*}}$
}

\begin{abstract}
Accumulating evidence suggests that various diseases, including many types of cancer, result from alteration of subcellular protein localization and compartmentalization. Therefore, it is worthwhile to expand our knowledge in subcellular trafficking of proteins, such as epidermal growth factor receptor (EGFR) and ErbB-2 of the receptor tyrosine kinases, which are highly expressed and activated in human malignancies and frequently correlated with poor prognosis. The well-characterized trafficking of cell surface EGFR is routed, via endocytosis and endosomal sorting, to either the lysosomes for degradation or back to the plasma membrane for recycling. A novel nuclear mode of EGFR signaling pathway has been gradually deciphered in which EGFR is shuttled from the cell surface to the nucleus after endocytosis, and there, it acts as a transcriptional regulator, transmits signals, and is involved in multiple biological functions, including cell proliferation, tumor progression, DNA repair and replication, and chemo- and radio-resistance. Internalized EGFR can also be transported from the cell surface to several intracellular compartments, such as the Golgi apparatus, the endoplasmic reticulum, and the mitochondria, in addition to the nucleus. In this review, we will summarize the functions of nuclear EGFR family and the potential pathways by which EGFR is trafficked from the cell surface to a variety of cellular organelles. A better understanding of the molecular mechanism of EGFR trafficking will shed light on both the receptor biology and potential therapeutic targets of anti-EGFR therapies for clinical application.
\end{abstract}

Keywords: EGFR family receptors, Nuclear translocation, Subcellular trafficking

\section{Review}

Introduction

Receptor tyrosine kinases (RTKs), which contain an extracellular ligand binding domain, a transmembrane domain, and an intracellular tyrosine kinase domain, mediate cellular signal transduction by extracellular ligand binding. The epidermal growth factor receptor (EGFR) family of RTKs consists of four members: EGFR/ ErbB-1/HER-1, ErbB-2/HER-2/neu, ErbB-3/HER-3, and ErbB-4/HER-4, and all except ErbB-3 are associated with tyrosine kinase activity. Upon ligand binding, EGFR family proteins dimerize by receptor homo-dimerization

\footnotetext{
* Correspondence: mhung@mdanderson.org

'Department of Molecular and Cellular Oncology, The University of Texas MD Anderson Cancer Center, Houston, TX 77030, USA

${ }^{2}$ Center for Molecular Medicine and Graduate Institute of Cancer Biology, China Medical University, Taichung, Taiwan
}

or hetero-dimerization and subsequently activate tyrosine kinase activity. Activated EGFR family receptors then trigger a myriad of downstream signaling pathways, such as phosphatidylinositol-3 kinase, mitogen-activated protein kinase, signal transducer and activator of transcription (STAT), phospholipase $\mathrm{C}$, and the modulation of calcium channels. These downstream signaling activities regulate proliferation, mobility, and differentiation in many different cell types [1-4].

All but ErbB-4 of the EGFR family of proteins are expressed and/or constitutively activated in human tumors of epithelial origin. This expression leads to aggressive tumor behavior, including cancer initiation, increased tumor growth/progression, poor patient outcome, metastasis, and chemo-resistance [5-8]. Unlike the other EGFRs, the oncogenic role of ErbB-4 in breast cancer is unclear since it appears to be correlated with prolonged patient survival and tumor growth suppression 
$[9,10]$. Accordingly, EGFR family receptors have been considered as effective targets for anti-cancer therapies. Both ectodomain-binding monoclonal antibodies and small-molecule tyrosine-kinase inhibitors (TKIs) targeting EGFR and ErbB-2 have been developed, and many of them are approved by the Food and Drug Administration.

Interestingly, in addition to their positions in traditional signaling cascades, numerous evidence to date from different groups indicate a unique translocation and the associated biological functions of the EGFR family receptors, by which they can be shuttled from the cell surface to the nucleus [11-35], termed membrane receptors in the nucleus (MRIN) [36]. The molecular mechanism underlying the cell surface membrane-to-nucleus trafficking of EGFR has been documented recently $[37,38]$. In this review, we will summarize recent discoveries in the MRIN field and discuss the subcellular trafficking pathways of the EGFR family proteins from the cell surface to a variety of cellular organelles, including the Golgi apparatus, the endoplasmic reticulum (ER), the mitochondria, as well as the nucleus.

\section{Discovery and current understandings of MRIN Nuclear EGFR detection and clinical relevance}

Nuclear expression of EGFR was first detected in hepatocytes during regeneration [39-42]. A full-length form of cell surface EGFR has been shown to be translocated to the nucleus, where evidence suggests that it is involved in transcriptional regulation, cell proliferation, DNA replication, DNA repair, and chemo- and radio-resistance [43-48]. In addition to ligand-dependent mechanisms, EGFR transport to the nucleus has also been associated with DNA damage events, including ionizing radiation, ultraviolet irradiation, cisplatin treatment, oxidative stress, heat treatment, and treatment with cetuximab/C225, a monoclonal anti-EGFR antibody [49-52]. Nuclear EGFR has been associated with poor clinical prognosis in diverse cancer types, including breast cancer, ovarian cancer, and oropharyngeal and esophageal squamous cell carcinomas [53-58].

\section{Nuclear EGFR in therapeutic resistance}

Nuclear EGFR has been shown to contribute to resistance to various cancer therapies, such as radiation, cisplatin, and cetuximab [59-61]. Moreover, dasatinib, a potent Src inhibitor, can block cetuximab- and radiationinduced EGFR nuclear translocation in head and neck squamous cell carcinoma [62]. Another report showed that lapatinib, a dual TKI of EGFR and HER2, inhibits the nuclear transport of EGFR and HER2 and sensitizes cancer cells to fluoropyrimidine by downregulating thymidylate synthase, which is frequently overexpressed in fluoropyrimidine-resistant cancer cells [63]. Recently, two related papers demonstrated that nuclear EGFR confers acquired resistance to an EGFR-TKI, gefitinib, by increasing the expression of breast cancer-resistant protein (BCRP), which is an ATP-binding cassette transporter that pumps anti-cancer drugs out of cells $[17,64]$. Combined evidence to date suggests that nuclear localization of EGFR contributes to therapeutic resistance to EGFR-targeting treatments.

\section{Nuclear translocation of EGFR variants}

EGFRvIII, a constitutively activated EGFR type III variant, was first identified in the nucleus in hormone-refractory prostate cancer and associated with poor patient survival [65]. EGFRvIII has also been detected in the nucleus of normal glial cells and primary glioblastomas, where it forms an oncogenic complex with STAT3 to mediate EGFRvIII-dependent glial transformation [26]. Another report showed that the nuclear EGFRvIII-STAT3 complex can activate cyclooxygenase-2 (COX-2) gene expression in glioblastoma cells [30]. Interestingly, an in-frame splicing EGFR variant that lacks multiple domains, called mLEEK, has recently been reported to function as a transcription factor in the nucleus [16].

\section{Nuclear translocation of ErbB-2}

The level of ErbB-2/neu has been shown increase in the nuclear area by treatment of heregulin, a glycoprotein that elevates tyrosine phosphorylation of the neu receptor [66]. The rat version of human ErbB-2, p185neu, was first reported to be located in the nucleus, where it is associated with transcriptional activity [67]. A full-length form of nuclear ErbB-2 is involved in COX2 transcriptional regulation via transactivating COX2 gene promoter in breast cancer cells [68]. More recently, it has been shown that nuclear ErbB-2 activates transcription of ribosomal RNA genes through association with RNA polymerase-I and $\beta$-actin to ribosomal DNA, leading to increased protein synthesis and cell growth [29]. In addition to nuclear ErbB-2 (p185 ${ }^{\text {ErbB-2}}$ ) as an intact molecule, ErbB-2 (p95), which lacks the $\mathrm{N}$-terminal extracellular domain, has also been found in the nucleus [69], where it contributes to acquired therapeutic resistance to ErbB-2 TKIs [70].

\section{Nuclear translocation of ErbB-3 and ErbB-4}

ErbB-3 exists as a full-length form in the nucleus [24]. Intriguingly, low expression of nuclear ErbB-3 is a predictor of a higher risk of biochemical recurrence in patients with prostate cancer [71,72]. A truncated form of the intracellular domain (ICD) of ErbB-4 undergoing $\gamma$-secretase-mediated cleavage has been found in the nucleus of cancer cells [20,73], whereas ErbB-4 has been detected as a full-length receptor in the nuclei of some normal cells [74,75]. The role of nuclear ErbB-4 ICD is still ambiguous but has been shown to be involved in both shorter patient survival [76] and improved patient response to tamoxifen therapy [77] for estrogen receptor- $\alpha$ positive cancers. According to the papers, nuclear 
cleavable ErbB-4 is associated with shorter survival than cell surface ErbB-4 in the estrogen receptor-positive subset of breast cancer patients, suggesting that the subcellular localization of ErbB-4 is correlated with clinical outcome [76]. On the other hand, researchers have demonstrated that nuclear ErbB-4 ICD acts as a co-activator of estrogen receptor- $\alpha$ and improves patient response to tamoxifen therapy [77]. Additionally, ErbB-4 ICD has been shown to enhance the ubiquitination and degradation of an oncogenic protein, $\mathrm{Hdm} 2$, following the increased expression of a tumor suppressor, p53 [78], while blocking Eto2-dependent transcriptional repression involved in cell differentiation [79]. Thus, the controversial role of ErbB-4 ICD as an oncogene or a tumor suppressor requires further systematic investigation.

\section{Nuclear translocation of cell surface receptors other than the EGFR family proteins}

A substantial body of evidence indicates that several fulllength RTKs and cell surface receptors other than EGFR family proteins are translocated to the nucleus, such as fibroblast growth factor receptor (FGFR), vascular endothelial growth factor receptor, insulin-like growth factor-1 receptor, cMet, TrkA, interleukin receptors, interferon- $\gamma$ receptor, and growth hormone receptors $[44,45,80]$. Recently, receptor tyrosine kinase-like orphan receptor 1 (Ror1), which belongs to the ROR RTK family, has been shown to be transported to the nucleus through the juxtamembrane domain [81]. In addition, prolactin-mediated nuclear translocation of cell surface prolactin receptor recruits a chromatin-modifying protein to activate Stat5a-driven gene expression [82]. Together, in addition to EGFR family, multiple RTKs have also been detected in the nucleus, raising MRIN as a general phenomenon.

\section{Nuclear detection of EGFR family ligands}

Ligands of the EGFR family, such as EGF, pro-transforming growth factor- $\alpha$, and pro-heparin-binding EGF-like growth factor, have been found in the nucleus [83-86]. Schwannoma-derived growth factor, which belongs to the EGF family, can also be detected in the nucleus, where it binds to A + T-rich DNA sequences, leading to a mitogenic response [87]. Furthermore, nuclear translocation of the ICD fragment of neuregulin-1, an ErbB-3/ErbB-4 ligand, results in increased neuronal survival by repressing the cell death response to several regulators [88]. Thus, not only RTKs, ligands can also be translocated into the nucleus, suggesting ligand/receptor association may also occur in the nucleus. In supporting of this notion, the EGF/EGFR complex was indeed detected in the nucleus using the cross-linking experiment between EGF and EGFR [48].

\section{Molecular and biological functions of nuclear EGFR family proteins}

Nuclear EGFR family as transcriptional co-activator

Members of the nuclear EGFR family that contain an intrinsic transactivation activity at the C-terminal acidic region, including EGFR, ErbB-2, and ErbB-4 [20,48,67,68], can function in transcriptional regulation to enhance target gene expression through activation of transcriptional factors. Several gene promoters have been identified as the targets of the nuclear EGFR family receptors (Figure 1), such as cyclin D1 [48], B-Myb [89], iNOS [90], Aurora-A [91], COX-2 [30], c-Myc [14], thymidylate synthase [63], and BCRP [17], which are involved in tumorigenesis, chromosome instability, and chemoresistance. Upon EGF stimulation, activated nuclear EGFR acts as a transcriptional co-activator, binding to an AT-rich response sequence (ATRS) of the cyclin D1 promoter and stimulating cyclin D1 expression [48]. A recent paper identified potential nuclear EGFR interacting proteins using an unbiased mass spectrometry approach: it showed that RNA helicase A (RHA) associates with nuclear EGFR and the EGFR-RHA complex activates cyclin D1 transcription through binding of RHA to the ATRS [92]. MUC1 has also been found to interact with nuclear EGFR and promote EGFR-mediated cyclin D1 gene expression [11]. Moreover, activated nuclear EGFR has been shown to bind to the ATRS motif and promote B-Myb, iNOS, COX-2, and Aurora-A genes through interaction with transcription factors, such as E2F1, STAT3, and STAT5A, respectively [30,89-91]. Recently, researchers demonstrated that EGFR is transported to the nucleus through serine phosphorylation by Akt, and the nuclear EGFR then targets multiple ATRSs on the BCRP promoter in gefitinibresistant cells, which is involved in chemo-resistance $[17,93]$. In addition, nuclear EGFR and HER2 activate thymidylate synthase gene transcription via binding to its promoter, and this interaction between EGFR/HER2 with thymidylate synthase promoter is blocked by a dual EGFR/ HER2-TKI, lapatinib [63]. A novel nuclear complex including EGFR together with c-Src kinase and STAT3 can associate with the c-Myc promoter in pancreatic cancer, suggesting that this heteromeric complex may regulate the c-Myc gene [14]. Nuclear EGFRvIII has also been found to cooperate with STAT3 to activate COX-2 gene expression in glioblastoma cells, resulting in glioma tumorigenesis $[26,30]$. In line with the studies of nuclear EGFR, nuclear ErbB-2 can transactivate COX2 gene expression through binding to a specific DNA element, the HER2-associated sequence, within the promoter, whereas the transcriptional factors involved remain to be identified [68]. In addition, the ICD of ErbB4 translocates to the nucleus upon ligand stimulation and associates with STAT5A to transactivate the $\beta$-casein gene promoter [94]. Nuclear ErbB-4 ICD has been shown to interact with 

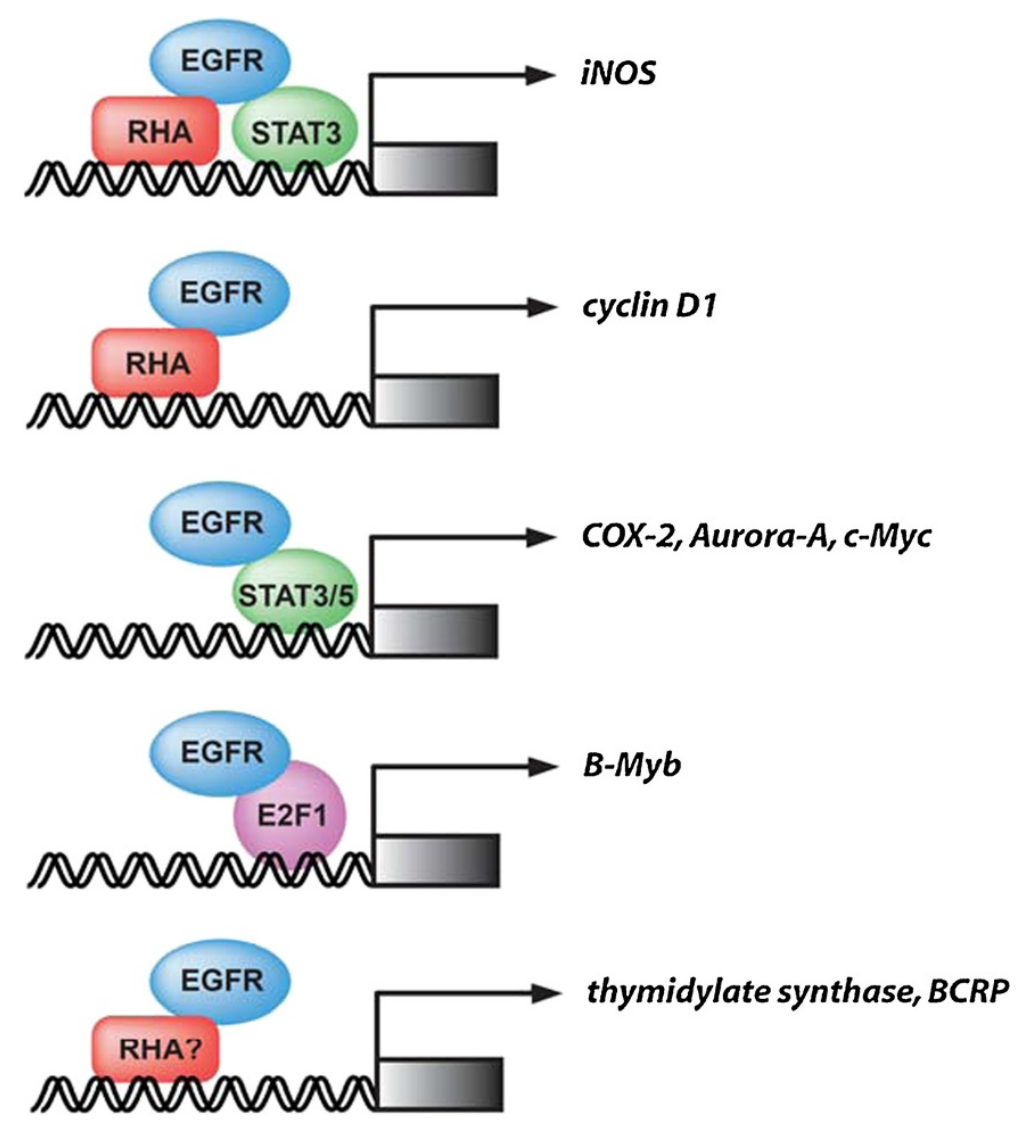

Figure 1 A summary of nuclear function of EGFR as a transcriptional co-activator. Nuclear EGFR can function in transcriptional regulation to enhance expression levels of target genes, including iNOS (A), cyclin D1 (B), COX-2 (C), Aurora-A (C), c-Myc (C), B-Myb (D), thymidylate synthase $(\mathbf{E})$, and BCRP $(\mathbf{E})$, through activation of transcriptional factors, such as STAT and E2F1. EGFR also associates with RHA in the nucleus, where the EGFR/RHA complex binds to the target gene promoter, including iNOS (A) and cyclinD1 (B), through the recruitment of RHA to the ATRS of the target gene promoter to mediate its transcriptional activation. In addition to RHA, EGFR is also recruited to the iNOS gene promoter through STAT3 to the STAT3-binding site (A). Whether RHA is involved in the nuclear EGFR-mediated activation of thymidylate synthase and BCRP (E) has not yet been explored.

Eto-2, a nuclear corepressor in breast cancer, and block Eto-2-dependent transcriptional repression [79]. A recent report characterizing EGFR as a DNA-binding protein using unbiased approaches [95] further supports the notion that the nuclear EGFR family plays a role in transcriptional regulation.

\section{Nuclear EGFR family as protein kinase involving protein- protein interaction}

Nuclear EGFR family receptors, except ErbB-3, maintain tyrosine kinase activity. Nuclear EGFR associates with and phosphorylates the chromatin-bound form of proliferative cell nuclear antigen (PCNA), which stabilizes PCNA protein, leading to DNA replication and DNA damage repair [19]. A series of studies showed that DNA damage pathways, such as those activated by ultraviolet irradiation or cisplatin treatment, can induce the interaction between nuclear EGFR and DNA-dependent protein kinase (DNA-PK) [15,50,60], which is a central enzyme of the nonhomologous end-joining repair of DNA double-strand breaks, contributing to DNA repair and chemo- and radio-resistance. It is not yet clear but worthwhile to determine whether EGFR phosphorylates DNA-PK to regulate its activity. Moreover, ErbB-2 is able to co-localize with the cyclin-dependent kinase $\mathrm{p} 34^{\mathrm{Cdc} 2}$ in both the cytoplasm and the nucleus, and subsequently phosphorylate it, leading to resistance to taxol treatment in breast cancer [96], suggesting that ErbB-2 functions as a kinase in the nucleus. Furthermore, ErbB-4 ICD fragment has been shown to interact with and phosphorylate the nuclear protein $\mathrm{Hdm} 2$, and consequently enhance Hdm2 ubiquitination, increase p53 transcriptional activity using a p21 luciferase reporter, and increase p53 and p21 expression [78]. 


\section{EGFR subcellular trafficking from the cell surface to different compartments}

The signaling duration and intensity of transmembrane RTKs stimulated by extracellular ligands is regulated by receptor endocytosis, which is characterized as a membrane and vesicular trafficking process. After ligand-induced endocytosis, cargo proteins carried in budding vesicles can be delivered from donor membranes to acceptor subcellular organelles through fusion pathways, by which RTKs and their cognate ligands are internalized into cytoplasmic vesicles and sequentially removed from the cell surface $[97,98]$. Accumulating evidence suggests that the internalized EGFR embedded within the early endosomes has several potential destinations via endosomal sorting. First, EGFR can be recycled back to the cell surface through either the recycling endosomes or a direct recycling pathway. Second, EGFR can be sorted into the late endosomes and subsequently degraded by lysosomes. In addition to the above well-characterized trafficking routes, a novel mode of the EGFR signaling pathway, in which EGFR after endocytosis can be transported from the cell surface to different compartments within cells, including the Golgi apparatus, the ER, the mitochondria, as well as the nucleus, has also been reported [25,27,44] (Figure 2). We will highlight the subcellular trafficking mechanism of EGFR in the following paragraphs.

\section{Vesicle trafficking of EGFR to the Golgi apparatus and to the ER}

Cargo proteins carried in budding vesicles after endocytosis can be sorted to the biosynthetic/secretory compartments, such as the Golgi apparatus and the ER, known as retrograde transport, which is involved in multiple cellular functions. The retrograde route from early endosomes to the Golgi apparatus occurs in several

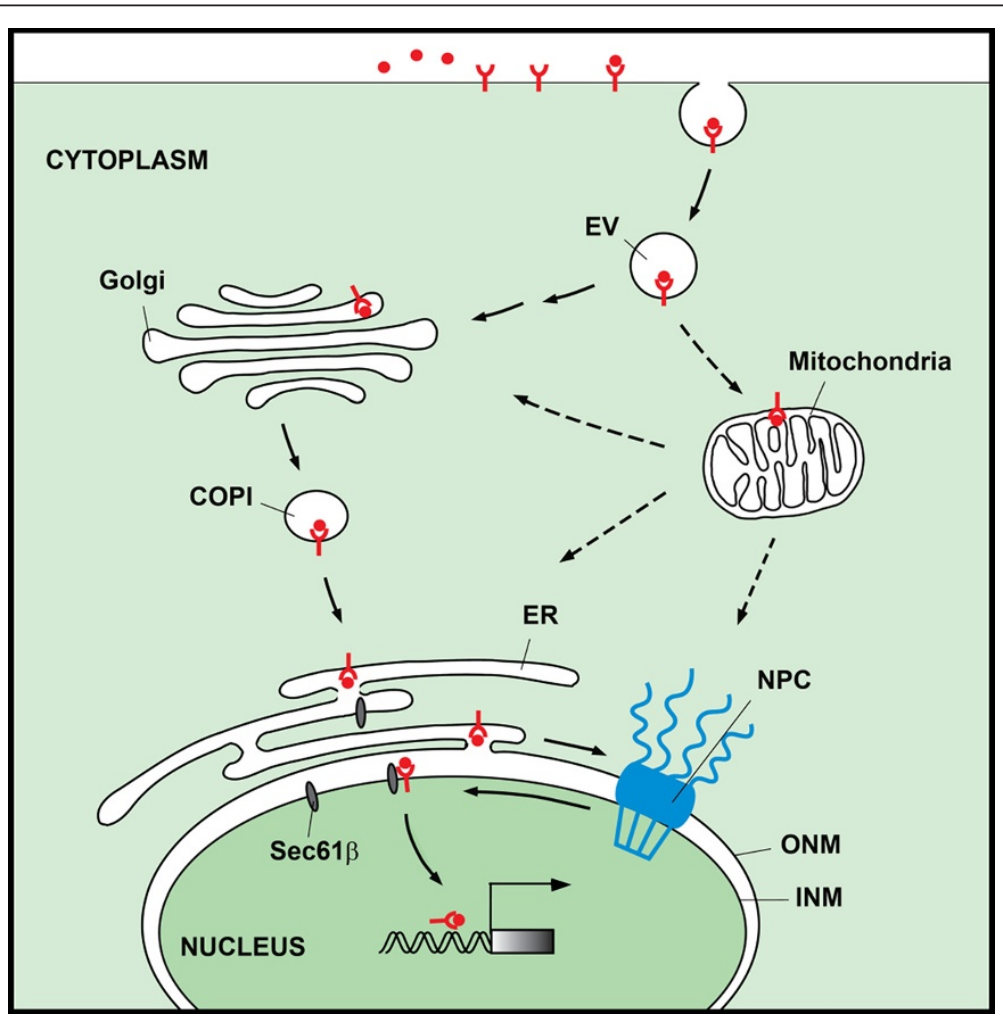

Figure $2 \mathrm{~A}$ diagram of the EGFR family receptors trafficking to different compartments. The endocytic vesicles carrying EGFR can be transported from the cell surface to several intracellular organelles, including the Golgi apparatus, the ER, the mitochondria, and the nucleus. It has been documented recently that COPI vesicle-mediated retrograde transport from the Golgi to the ER is involved in the EGFR nuclear trafficking. Integral EGFR inserted into the ER membrane is targeted to the INM of the nuclear envelope (NE) through the ONM and NPC via a model of integral trafficking from the ER to the NE transport (INTERNET). The INM-embedded EGFR can be released from the lipid bilayer to the nucleoplasm within the nucleus by the association with the translocon Sec61 $\beta$ located in the INM. In addition to the nuclear import of cell surface EGFR, the internalized EGFR can also be trafficked to the mitochondria; however, the molecular mechanism underlying the cell surface-tomitochondria trafficking of EGFR remains unclear. Whether the localization of EGFR in the mitochondria is involved in the EGFR trafficking to the Golgi, the ER, and the nucleus has not yet been explored. The scale of the diagram does not reflect the relative sizes of different molecules or subcellular structures. EV, endocytic vesicle; COPI: coat protein complex I; NPC, nuclear pore complex; ER, endoplasmic reticulum; ONM, outer nuclear membrane; INM, inner nuclear membrane. 
mammalian cargo proteins [99] while that to the ER is commonly used by exogenous viruses and toxins [100]. Recently, researchers identified the first example of retrograde trafficking, in which EGFR is transported from the Golgi to the ER to regulate the nuclear transport of cell surface EGFR RTK [37]. Upon EGF treatment, full-length EGFR anchors to the membranes of the Golgi and the ER, with the C-terminus exposed to the cytoplasm and the N-terminus masked inside the Golgi and ER lumen [37]. Another group of researchers reported that EGFR is trafficked from the cell surface to the ER in response to EGF [32]. It has also been welldocumented that coat proteins, including coat protein complex I (COPI) involved in the Golgi-to-ER retrograde transport and COPII in the ER-to-Golgi anterograde transport, play a central role in vesicular transport to target its intracellular destination [101-103]. Wang et al. [37] reported that $\gamma$-COP, one of the subunits of the COPI coatomer, associates with EGFR and mediates EGF-dependent EGFR nuclear transport. Together, these findings suggest that endosomal membrane-embedded cell surface EGFR in a membrane-associated environment travels from the cell surface to the nucleus within the Golgi and ER membranes via COPI-mediated vesicle trafficking. Most recently, an interesting report showed that COPI acts not only in vesicular retrograde transport but also, unexpectedly, in tubular formation, which is involved in anterograde intra-Golgi transport [104]. It would be interesting to determine the physiological roles of COPI tubules to further expand our knowledge on how the COPI complex regulates subcellular cargo sorting.

\section{EGFR trafficking to the mitochondria}

Upon EGF treatment, full-length EGFR anchors to the mitochondria, where it associates with cytochrome c oxidase subunit II, a key component of the oxidative phosphorylation cascade in regulating apoptosis through cytochrome c release from the mitochondria [105,106]. In addition, clathrin-mediated endocytosis, c-Src kinase activity, and a putative mitochondrial localization signal within the juxtamembrane domain of EGFR are involved in EGFR translocation to the mitochondria [106]. The alternate subcellular localization of EGFR to the mitochondria may contribute to cellular survival in modulating cytochrome $\mathrm{c}$ oxidase subunit II-dependent mitochondrial functions. A recent paper showed that both EGFR and EGFRvIII can be translocated to the mitochondria after treatment of apoptosis inducers and an EGFR-tyrosine kinase inhibitor, and the mitochondrial targeting of these receptors is responsible for drug resistance [107]. Furthermore, cetuximab has also been shown to induce mitochondrial accumulation of EGFRvIII [108], suggesting that mitochondrial EGFR/EGFRvIII plays a role in therapeutic response to EGFR-targeting drugs.

However, how EGFR is transported to the mitochondria remains unclear. Further study is required to determine whether EGFR is integrated into the mitochondrial membrane through endosomal membrane fusion with the mitochondria or via other potential pathways.

\section{EGFR trafficking to the nucleus}

EGFR family receptors have been discovered to be transported to the nucleus, where they exist as full-length or truncated forms and exert a number of functions, as described in the previous sections (Table 1). However, the trafficking mechanism for the nuclear transport of endosome-embedded EGFR family has been overlooked for decades. In addition to the recent paper reporting that COPI-mediated retrograde trafficking regulates nuclear translocation of EGFR [37], there have reports that identified the putative nuclear localization signals (NLSs) within all of the EGFR family members $[24,30,68,90,94]$. Researchers have further characterized a tripartite NLS of EGFR, which is different from the traditional mono- and bipartite NLSs, contains three clusters of basic amino acids, and is conversed within the juxtamembrane regions among the EGFR family [109]. It has been demonstrated that NLS and importin- $\beta$ are

Table 1 Existence of EGFR family receptors in the nucleus

\begin{tabular}{|c|c|c|c|c|}
\hline EGFR family receptor & Type & Size (kDa) & Cell/Tissue detection & Reference \\
\hline EGFR & Full-length & 170 & $\begin{array}{l}\text { hepatocyte, breast, pancreatic, head and neck, } \\
\text { glioblastoma, lung, and skin cancers, etc. }\end{array}$ & {$[12,14,22,28,30,38,39,49]$} \\
\hline EGFRvIII & In-frame deletion & 145 & normal glial cells, glioblastoma, prostate cancer & {$[26,30,65]$} \\
\hline EGFR variant mLEEK & In-frame splice & 45 & glioblastoma & {$[16]$} \\
\hline ErbB-2: p185 & Full-length & 185 & breast cancer & {$[29,68,110]$} \\
\hline ErbB-2: $p 95^{\text {ErbB-2 }}$ & N-terminal truncation & 95 & breast cancer & {$[69,70]$} \\
\hline ErbB-3 & Full-length & 185 & $\begin{array}{l}\text { nonmalignant epithelial cells, breast cancer, } \\
\text { prostate cancer }\end{array}$ & {$[24,65,71,72]$} \\
\hline ErbB-4 & Full-length & 180 & normal cells: brain cells, endothelial cells & {$[74,75]$} \\
\hline ErbB-4 ICD & N-terminal truncation & 80 & breast cancer, prostate cancer, embryonic brain & {$[20,65,73,76]$} \\
\hline
\end{tabular}


involved in the nuclear translocation of EGFR and ErbB-2 $[110,111]$, in which importin- $\beta$ forms a complex with NLS-harboring molecules and is responsible for nuclear translocation through binding to the nucleoporins of nuclear pore complexes. Furthermore, receptor endocytosis and endosomal sorting through association with early endosomal markers in the nucleus are also required for nuclear translocation of EGFR and ErbB-2 [110,111]. Interestingly, in addition to its localization in the nucleoplasm within the nucleus, ErbB-2 has been observed specifically in the nucleolus, where it associates with RNA polymerase-I [29]. Further investigations of the potential trafficking mechanism of ErbB-2 to the nucleolus and of the identity of EGFR family receptors other than ErbB-2 are warranted. Moreover, the exportin CRM1 has been shown to be involved in the nuclear export of cell surface RTKs, including EGFR, ErbB-2, and ErbB-3, although their nuclear export signals have not yet been identified $[24,110,111]$.

\section{Trafficking of EGFR from the inner nuclear membrane to the nucleoplasm}

EGFR appears to be present in the inner nuclear membrane (INM) or nuclear matrix [112,113]; however, the exact trafficking mechanism in INM translocation is unclear. Recently, it has been shown that, upon EGF stimulation, cell surface EGFR is targeted to the INM through a mechanism termed INTERNET, which stands for the integral trafficking from the ER to the nuclear envelope transport, pathway $[38,44]$. Furthermore, the INM-anchored EGFR has been proposed to be extracted from the INM to the nucleoplasm by a translocon Sec61 $\beta$-dependent process, in which Sec61 $\beta$, traditionally associated with the ER, displays a previously unrecognized location and role in regulating EGFR nuclear transport via the association with EGFR in the INM [38]. The newly identified Sec61 $\beta$ function provides a plausible explanation for how the membrane-bound cell surface EGFR remains in a membrane-associated environment while it is translocated from the lipid bilayer of the INM to the nucleus. But beyond our preliminary understanding of the Sec61 $\beta$-associated pathway in the nucleus, the trafficking mechanism remains largely unexplored. It is worthwhile to mention that whether the intra-nuclear EGFR represents as a soluble receptor free of membrane is still unclear; therefore, one possible mechanism raised is that an endocytosis-like mechanism in the nuclear envelope transports EGFR from the INM to the nucleoplasm, where EGFR remains nuclear membrane-embedded. A more systematic study is required to further address this hypothesis. Interestingly, Sec61 $\beta$, which is traditionally thought to be localized in the ER, has been proposed to extract EGFR from lipid layers of the ER membrane for delivery to the cytoplasm via ER-associated degradation pathway. At that point, cytoplasmic EGFR can be transported to the nucleus through the association of importin- $\beta$ [32]. However, this Sec61 $\beta$-mediated ERassociated degradation model in regulating EGFR nuclear trafficking needs to be further verified since researchers could not detect EGFR in the cytoplasm in EGF-treated cells [32].

\section{Conclusions}

Multiple integral membrane proteins, including all members of EGFR family, have been reported to function in the nucleus. Recently, researchers discovered a logical route for the nuclear translocation of EGFR in response to EGF, in which cell surface EGFR travels to the nucleus, all the way in a membrane-bound environment, through the Golgi-to-ER retrograde pathway and INTERNET model to the INM in the nucleus $[37,38]$. The major questions yet to be investigated include at least the following: First, how is EGFR embedded in the endosomal membrane shuttled to the Golgi apparatus? One proposal is that the small GTPase protein Rab7b is essential for retrograde trafficking from the endosomes to the Golgi [114]. Whether specific Rab proteins are involved in EGFR trafficking to the nucleus needs to be determined. Second, does membrane-bound trafficking serve as a general mechanism for nuclear transport of other RTKs and cell surface receptors? Since FGFR-1 has an atypical transmembrane domain, which functions not only as a transmembrane RTK but also as a soluble cytoplasmic protein [115-117], unlike the EGFR family proteins, it may be useful to compare the trafficking mechanism of FGFR-1 nuclear translocation with that of EGFR. Last, does subcellular trafficking of EGFR to different compartments contribute to their different roles? Investigating systematically how cell surface RTKs are transported to various destinations will advance our knowledge of their unique functions of RTKs in different cellular compartments. Since many of these RTKs are therapeutic targets, the areas of research may have important clinical implication.

\footnotetext{
Abbreviations

RTKs: receptor tyrosine kinases; EGFR: epidermal growth factor receptor; STAT: signal transducer and activator of transcription; TKls: tyrosine-kinase inhibitors; MRIN: membrane receptors in the nucleus; ER: endoplasmic reticulum; BCRP: breast cancer-resistant protein; COX-2: cyclooxygenase-2; FGFR: fibroblast growth factor receptor; ATRS: AT-rich response sequence; RHA: RNA helicase A; PCNA: proliferative cell nuclear antigen; DNA-PK: DNAdependent protein kinase; COPI: coat protein complex I; NLSs: nuclear localization signals; INTERNET: integral trafficking from the ER to the nuclear envelope transport; ERAD: ER-associated degradation.
} 


\section{Acknowledgements}

This review is based on my Presidential Award Lecture at the 2011 SCBA biannual meeting in Guangzhou, China. We thank Dr. Jung-Mao Hsu for the diagram of the proposed model. We also thank Dr. Walter J. Pagel at Department of Scientific Publications and Dr. Jennifer L. Hsu for editing this manuscript. This current study was supported by the National Institutes of Health Grants NIH RO1 CA 109311; NIH PO1 CA 099031; the National Breast Cancer Foundation, Inc.; and the Sister Institutional Fund from China Medical University Hospital and MD Anderson Cancer Center. This work was also supported by the Cancer Research Center of Excellence Grant DOH101-TD-C111-005; and NSC99-2632-B-039-001-MY3 from Taiwan.

\section{Authors' contributions}

Y-NW and M-CH outlined the manuscript. Y-NW wrote the draft version and $\mathrm{M}-\mathrm{CH}$ finalized the manuscript. Both authors read and approved the final manuscript.

Received: 12 January 2012 Accepted: 20 April 2012

Published: 20 April 2012

\section{References}

1. Avraham R, Yarden Y: Feedback regulation of EGFR signalling: decision making by early and delayed loops. Nat Rev Mol Cell Biol 2011, 12:104-117.

2. Citri A, Yarden Y: EGF-ERBB signalling: towards the systems level. Nat Rev Mol Cell Biol 2006, 7:505-516.

3. Lo HW, Hsu SC, Hung MC: EGFR signaling pathway in breast cancers: from traditional signal transduction to direct nuclear translocalization. Breast Cancer Res Treat 2006, 95:211-218.

4. Huang PH, Xu AM, White FM: Oncogenic EGFR signaling networks in glioma. Sci Signal 2009, 2:6.

5. Irmer D, Funk JO, Blaukat A: EGFR kinase domain mutations - functional impact and relevance for lung cancer therapy. Oncogene 2007, 26:5693-5701.

6. Gazdar AF: Activating and resistance mutations of EGFR in non-small-cell lung cancer: role in clinical response to EGFR tyrosine kinase inhibitors. Oncogene 2009, 28(Suppl 1):S24-S31.

7. Hynes NE, MacDonald G: ErbB receptors and signaling pathways in cancer. Curr Opin Cell Biol 2009, 21:177-184.

8. Linardou H, Dahabreh IJ, Bafaloukos D, Kosmidis P, Murray S: Somatic EGFR mutations and efficacy of tyrosine kinase inhibitors in NSCLC. Nat Rev Clin Oncol 2009, 6:352-366.

9. Jones FE: HER4 intracellular domain (4ICD) activity in the developing mammary gland and breast cancer. J Mammary Gland Biol Neoplasia 2008, 13:247-258

10. Muraoka-Cook RS, Feng SM, Strunk KE, Earp HS 3rd: ErbB4/HER4: role in mammary gland development, differentiation and growth inhibition. $J$ Mammary Gland Biol Neoplasia 2008, 13:235-246.

11. Bitler BG, Goverdhan A, Schroeder JA: MUC1 regulates nuclear localization and function of the epidermal growth factor receptor. J Cell Sci 2010, 123:1716-1723.

12. Merlin J, Stechly L, de Beauce S, Monte D, Leteurtre E, van Seuningen I, Huet G, Pigny P: Galectin-3 regulates MUC1 and EGFR cellular distribution and EGFR downstream pathways in pancreatic cancer cells. Oncogene 2011, 30:2514-2525.

13. De Angelis Campos AC, Rodrigues MA, de Andrade C, de Goes AM, Nathanson MH, Gomes DA: Epidermal growth factor receptors destined for the nucleus are internalized via a clathrin-dependent pathway. Biochem Biophys Res Commun 2011, 412:341-346.

14. Jaganathan S, Yue P, Paladino DC, Bogdanovic J, Huo Q, Turkson J: A functional nuclear epidermal growth factor receptor, SRC and Stat3 heteromeric complex in pancreatic cancer cells. PLoS One 2011, 6:e19605.

15. Liccardi G, Hartley JA, Hochhauser D: EGFR nuclear translocation modulates DNA repair following cisplatin and ionizing radiation treatment. Cancer Res 2011, 71:1103-1114.

16. Piccione EC, Lieu TJ, Gentile CF, Williams TR, Connolly AJ, Godwin AK, Koong $A C$, Wong AJ: A novel epidermal growth factor receptor variant lacking multiple domains directly activates transcription and is overexpressed in tumors. Oncogene 2011. doi:10.1038/onc.2011.465.

17. Huang WC, Chen YJ, Li LY, Wei YL, Hsu SC, Tsai SL, Chiu PC, Huang WP, Wang YN, Chen $\mathrm{CH}$, et al: Nuclear translocation of epidermal growth factor receptor by Akt-dependent phosphorylation enhances breast cancer-resistant protein expression in gefitinib-resistant cells. J Biol Chem 2011, 286:20558-20568.

18. Cornelissen B, Darbar S, Hernandez R, Kersemans V, Tullis I, Barber PR, Smart S, Vojnovic B, Reilly R, Vallis KA: ErbB-2 blockade and prenyltransferase inhibition alter epidermal growth factor and epidermal growth factor receptor trafficking and enhance (111) In-DTPA-hEGF Auger electron radiation therapy. J Nucl Med 2011, 52:776-783.

19. Wang SC, Nakajima Y, Yu YL, Xia W, Chen CT, Yang CC, Mclntush EW, Li LY, Hawke DH, Kobayashi R, Hung MC: Tyrosine phosphorylation controls PCNA function through protein stability. Nat Cell Biol 2006, 8:1359-1368

20. Ni CY, Murphy MP, Golde TE, Carpenter G: gamma -Secretase cleavage and nuclear localization of ErbB-4 receptor tyrosine kinase. Science 2001, 294:2179-2181.

21. Wanner G, Mayer C, Kehlbach R, Rodemann HP, Dittmann K: Activation of protein kinase Cepsilon stimulates DNA-repair via epidermal growth factor receptor nuclear accumulation. Radiother Oncol 2008, 86:383-390.

22. Das AK, Chen BP, Story MD, Sato M, Minna JD, Chen DJ, Nirodi CS: Somatic mutations in the tyrosine kinase domain of epidermal growth factor receptor (EGFR) abrogate EGFR-mediated radioprotection in non-small cell lung carcinoma. Cancer Res 2007, 67:5267-5274.

23. Kim J, Jahng WJ, Di Vizio D, Lee JS, Jhaveri R, Rubin MA, Shisheva A, Freeman MR: The phosphoinositide kinase PIKfyve mediates epidermal growth factor receptor trafficking to the nucleus. Cancer Res 2007, 67:9229-9237

24. Offterdinger M, Schofer C, Weipoltshammer K, Grunt TW: c-erbB-3: a nuclear protein in mammary epithelial cells. J Cell Biol 2002, 157:929-939.

25. Massie C, Mills IG: The developing role of receptors and adaptors. Nat Rev Cancer 2006, 6:403-409.

26. de la Iglesia N, Konopka G, Puram SV, Chan JA, Bachoo RM, You MJ, Levy DE, Depinho RA, Bonni A: Identification of a PTEN-regulated STAT3 brain tumor suppressor pathway. Genes Dev 2008, 22:449-462.

27. Mosesson Y, Mills GB, Yarden Y: Derailed endocytosis: an emerging feature of cancer. Nat Rev Cancer 2008, 8:835-850.

28. Li C, lida M, Dunn EF, Wheeler DL: Dasatinib blocks cetuximab- and radiation-induced nuclear translocation of the epidermal growth factor receptor in head and neck squamous cell carcinoma. Radiother Oncol 2010, 97:330-337.

29. Li LY, Chen H, Hsieh YH, Wang YN, Chu HJ, Chen YH, Chen HY, Chien PJ, Ma $\mathrm{HT}$, Tsai HC, et al: Nuclear ErbB2 enhances translation and cell growth by activating transcription of ribosomal RNA genes. Cancer Res 2011, 71:4269-4279.

30. Lo HW, Cao X, Zhu H, Ali-Osman F: Cyclooxygenase-2 is a novel transcriptional target of the nuclear EGFR-STAT3 and EGFRvIlI-STAT3 signaling axes. Mol Cancer Res 2010, 8:232-245.

31. Dittmann K, Mayer C, Fehrenbacher B, Schaller M, Kehlbach R, Rodemann HP: Nuclear EGFR shuttling induced by ionizing radiation is regulated by phosphorylation at residue Thr654. FEBS Lett 2010, 584:3878-3884.

32. Liao HJ, Carpenter G: Role of the Sec61 translocon in EGF receptor trafficking to the nucleus and gene expression. Mol Biol Cell 2007 , 18:1064-1072

33. Li CF, Fang FM, Wang JM, Tzeng CC, Tai HC, Wei YC, Li SH, Lee YT, Wang YH, Yu SC, et al: EGFR Nuclear Import in Gallbladder Carcinoma: Nuclear Phosphorylated EGFR Upregulates iNOS Expression and Confers Independent Prognostic Impact. Ann Surg Oncol 2011 19:443-454.

34. Dekanic A, Dobrila Dintinjan R, Budisavljevic I, Pecanic S, Zuvic Butorac M, Jonjic N: Strong nuclear EGFR expression in colorectal carcinomas is associated with cyclin-D1 but not with gene EGFR amplification. Diagn Pathol 2011, 6:108

35. Nowsheen S, Bonner JA, Yang ES: The poly(ADP-Ribose) polymerase inhibitor ABT-888 reduces radiation-induced nuclear EGFR and augments head and neck tumor response to radiotherapy. Radiother Oncol 2011, 99:331-338.

36. Wang SC, Hung MC: Nuclear translocation of the epidermal growth factor receptor family membrane tyrosine kinase receptors. Clin Cancer Res 2009, 15:6484-6489.

37. Wang YN, Wang $H$, Yamaguchi $H$, Lee HJ, Lee HH, Hung MC: COPImediated retrograde trafficking from the Golgi to the ER regulates EGFR nuclear transport. Biochem Biophys Res Commun 2010, 399:498-504. 
38. Wang YN, Yamaguchi H, Huo L, Du Y, Lee HJ, Lee HH, Wang H, Hsu JM, Hung MC: The translocon Sec61beta localized in the inner nuclear membrane transports membrane-embedded EGF receptor to the nucleus. J Biol Chem 2010, 285:38720-38729.

39. Marti U, Burwen SJ, Wells A, Barker ME, Huling S, Feren AM, Jones AL: Localization of epidermal growth factor receptor in hepatocyte nuclei. Hepatology 1991, 13:15-20.

40. Marti U, Hug M: Acinar and cellular distribution and mRNA expression of the epidermal growth factor receptor are changed during liver regeneration. J Hepatol 1995, 23:318-327.

41. Marti U, Ruchti C, Kampf J, Thomas GA, Williams ED, Peter HJ, Gerber H, Burgi U: Nuclear localization of epidermal growth factor and epidermal growth factor receptors in human thyroid tissues. Thyroid 2001, 11:137-145.

42. Marti $U$, Wells $A$ : The nuclear accumulation of a variant epidermal growth factor receptor (EGFR) lacking the transmembrane domain requires coexpression of a full-length EGFR. Mol Cell Biol Res Commun 2000, 3:8-14.

43. Dittmann K, Mayer C, Rodemann HP: Nuclear EGFR as novel therapeutic target: insights into nuclear translocation and function. Strahlenther Onkol 2010, 186:1-6.

44. Wang YN, Yamaguchi H, Hsu JM, Hung MC: Nuclear trafficking of the epidermal growth factor receptor family membrane proteins. Oncogene 2010, 29:3997-4006.

45. Carpenter G, Liao HJ: Trafficking of receptor tyrosine kinases to the nucleus. Exp Cell Res 2009, 315:1556-1566.

46. Brand TM, lida M, Li C, Wheeler DL: The nuclear epidermal growth factor receptor signaling network and its role in cancer. Discov Med 2011, 12:419-432.

47. Lo HW: Nuclear mode of the EGFR signaling network: biology, prognostic value, and therapeutic implications. Discov Med 2010, 10:44-51.

48. Lin SY, Makino K, Xia W, Matin A, Wen Y, Kwong KY, Bourguignon L, Hung MC: Nuclear localization of EGF receptor and its potential new role as a transcription factor. Nat Cell Biol 2001, 3:802-808.

49. Xu Y, Shao Y, Zhou J, Voorhees JJ, Fisher GJ: Ultraviolet irradiation-induces epidermal growth factor receptor (EGFR) nuclear translocation in human keratinocytes. J Cell Biochem 2009, 107:873-880.

50. Dittmann K, Mayer C, Fehrenbacher B, Schaller M, Raju U, Milas L, Chen DJ, Kehlbach R, Rodemann HP: Radiation-induced epidermal growth factor receptor nuclear import is linked to activation of DNA-dependent protein kinase. J Biol Chem 2005, 280:31182-31189.

51. Liao HJ, Carpenter G: Cetuximab/C225-induced intracellular trafficking of epidermal growth factor receptor. Cancer Res 2009, 69:6179-6183.

52. Dittmann K, Mayer C, Fehrenbacher B, Schaller M, Kehlbach R, Rodemann HP: Nuclear epidermal growth factor receptor modulates cellular radiosensitivity by regulation of chromatin access. Radiother Oncol 2011, 99:317-322

53. Xia W, Wei Y, Du Y, Liu J, Chang B, Yu YL, Huo LF, Miller S, Hung MC: Nuclear expression of epidermal growth factor receptor is a novel prognostic value in patients with ovarian cancer. Mol Carcinog 2009, 48:610-617.

54. Hadzisejdic I, Mustac E, Jonjic N, Petkovic M, Grahovac B: Nuclear EGFR in ductal invasive breast cancer: correlation with cyclin-D1 and prognosis. Mod Pathol 2010, 23:392-403.

55. Hoshino M, Fukui H, Ono Y, Sekikawa A, Ichikawa K, Tomita S, Imai Y, Imura J, Hiraishi H, Fujimori T: Nuclear expression of phosphorylated EGFR is associated with poor prognosis of patients with esophageal squamous cell carcinoma. Pathobiology 2007, 74:15-21.

56. Lo HW, Xia W, Wei Y, Ali-Seyed M, Huang SF, Hung MC: Novel prognostic value of nuclear epidermal growth factor receptor in breast cancer. Cancer Res 2005, 65:338-348.

57. Psyrri A, Egleston B, Weinberger P, Yu Z, Kowalski D, Sasaki C, Haffty B, Rimm $D$, Burtness B: Correlates and determinants of nuclear epidermal growth factor receptor content in an oropharyngeal cancer tissue microarray. Cancer Epidemiol Biomarkers Prev 2008, 17:1486-1492.

58. Psyrri A, Yu Z, Weinberger PM, Sasaki C, Haffty B, Camp R, Rimm D, Burtness BA: Quantitative determination of nuclear and cytoplasmic epidermal growth factor receptor expression in oropharyngeal squamous cell cancer by using automated quantitative analysis. Clin Cancer Res 2005, 11:5856-5862.

59. Dittmann KH, Mayer C, Ohneseit PA, Raju U, Andratschke NH, Milas L, Rodemann HP: Celecoxib induced tumor cell radiosensitization by inhibiting radiation induced nuclear EGFR transport and DNA-repair: a COX-2 independent mechanism. Int J Radiat Oncol Biol Phys 2008, 70:203-212.

60. Hsu SC, Miller SA, Wang Y, Hung MC: Nuclear EGFR is required for cisplatin resistance and DNA repair. Am J Transl Res 2009, 1:249-258.

61. Li C, lida M, Dunn EF, Ghia AJ, Wheeler DL: Nuclear EGFR contributes to acquired resistance to cetuximab. Oncogene 2009, 28:3801-3813.

62. Li C, lida M, Dunn EF, Wheeler DL: Dasatinib blocks cetuximab- and radiation-induced nuclear translocation of the epidermal growth factor receptor in head and neck squamous cell carcinoma. Radiother Oncol 2010, 97:330-337.

63. Kim HP, Yoon YK, Kim JW, Han SW, Hur HS, Park J, Lee JH, Oh DY, Im SA, Bang YJ, Kim TY: Lapatinib, a dual EGFR and HER2 tyrosine kinase inhibitor, downregulates thymidylate synthase by inhibiting the nuclear translocation of EGFR and HER2. PLOS One 2009, 4:e5933.

64. Chen YJ, Huang WC, Wei YL, Hsu SC, Yuan P, Lin HY, Wistuba II, Lee JJ, Yen CJ, Su WC, et al: Elevated BCRP/ABCG2 expression confers acquired resistance to gefitinib in wild-type EGFR-expressing cells. PLoS One 2011, 6:e21428.

65. Edwards J, Traynor P, Munro AF, Pirret CF, Dunne B, Bartlett JM: The role of HER1-HER4 and EGFRvIll in hormone-refractory prostate cancer. Clin Cancer Res 2006, 12:123-130.

66. Bacus SS, Gudkov AV, Zelnick CR, Chin D, Stern R, Stancovski I, Peles E, BenBaruch N, Farbstein H, Lupu R, et al: Neu differentiation factor (heregulin) induces expression of intercellular adhesion molecule 1: implications for mammary tumors. Cancer Res 1993, 53:5251-5261.

67. Xie Y, Hung MC: Nuclear localization of p185neu tyrosine kinase and its association with transcriptional transactivation. Biochem Biophys Res Commun 1994, 203:1589-1598.

68. Wang SC, Lien HC, Xia W, Chen IF, Lo HW, Wang Z, Ali-Seyed M, Lee DF, Bartholomeusz G, Ou-Yang F, et al: Binding at and transactivation of the COX-2 promoter by nuclear tyrosine kinase receptor ErbB-2. Cancer Cell 2004, 6:251-261.

69. Scaltriti M, Rojo F, Ocana A, Anido J, Guzman M, Cortes J, Di Cosimo S, Matias-Guiu X: Ramon y Cajal S, Arribas J, Baselga J: Expression of p95HER2, a truncated form of the HER2 receptor, and response to anti-HER2 therapies in breast cancer. J Natl Cancer Inst 2007, 99:628-638.

70. Xia W, Liu Z, Zong R, Liu L, Zhao S, Bacus SS, Mao Y, He J, Wulfkuhle JD, Petricoin EF 3rd: et al: Truncated ErbB2 expressed in tumor cell nuclei contributes to acquired therapeutic resistance to ErbB2 kinase inhibitors. Mol Cancer Ther 2011, 10:1367-1374.

71. Koumakpayi IH, Diallo JS, Le Page C, Lessard L, Filali-Mouhim A, Begin LR, Mes-Masson AM, Saad F: Low nuclear ErbB3 predicts biochemical recurrence in patients with prostate cancer. BJU Int 2007, 100:303-309.

72. Koumakpayi IH, Diallo JS, Le Page C, Lessard L, Gleave M, Begin LR, MesMasson AM, Saad F: Expression and nuclear localization of ErbB3 in prostate cancer. Clin Cancer Res 2006, 12:2730-2737.

73. Sardi SP, Murtie J, Koirala S, Patten BA, Corfas G: Presenilin-dependent ErbB4 nuclear signaling regulates the timing of astrogenesis in the developing brain. Cell 2006, 127:185-197.

74. Thompson M, Lauderdale S, Webster MJ, Chong VZ, McClintock B, Saunders R, Weickert CS: Widespread expression of ErbB2, ErbB3 and ErbB4 in nonhuman primate brain. Brain Res 2007, 1139:95-109.

75. Bueter W, Dammann O, Zscheppang K, Korenbaum E, Dammann CE: ErbB receptors in fetal endothelium-a potential linkage point for inflammation-associated neonatal disorders. Cytokine 2006, 36:267-275.

76. Junttila T, Sundvall M, Lundin M, Lundin J, Tanner M, Harkonen P, Joensuu $\mathrm{H}$, Isola J, Elenius K: Cleavable ErbB4 isoform in estrogen receptorregulated growth of breast cancer cells. Cancer Res 2005, 65:1384-1393.

77. Naresh A, Thor AD, Edgerton SM, Torkko KC, Kumar R, Jones FE: The HER4/ $4 \mathrm{ICD}$ estrogen receptor coactivator and $\mathrm{BH} 3$-only protein is an effector of tamoxifen-induced apoptosis. Cancer Res 2008, 68:6387-6395.

78. Arasada RR, Carpenter G: Secretase-dependent tyrosine phosphorylation of Mdm2 by the ErbB-4 intracellular domain fragment. J Biol Chem 2005, 280:30783-30787.

79. Linggi B, Carpenter G: ErbB-4 s80 intracellular domain abrogates ETO2dependent transcriptional repression. J Biol Chem 2006, 281:25373-25380.

80. Lo HW, Hung MC: Nuclear EGFR signalling network in cancers: linking EGFR pathway to cell cycle progression, nitric oxide pathway and patient survival. Br J Cancer 2006, 94:184-188. 
81. Tseng HC, Lyu PC, Lin WC: Nuclear localization of orphan receptor protein kinase (Ror1) is mediated through the juxtamembrane domain. BMC Cell Biol 2010, 11:48.

82. Fiorillo AA, Medler TR, Feeney YB, Liu Y, Tommerdahl KL, Clevenger CV: HMGN2 inducibly binds a novel transactivation domain in nuclear PRLr to coordinate Stat5a-mediated transcription. Mol Endocrinol 2011, 25:1550-1564

83. Raper SE, Burwen SJ, Barker ME, Jones AL: Translocation of epidermal growth factor to the hepatocyte nucleus during rat liver regeneration. Gastroenterology 1987, 92:1243-1250.

84. Schausberger E, Eferl R, Parzefall W, Chabicovsky M, Breit P, Wagner EF, Schulte-Hermann R, Grasl-Kraupp B: Induction of DNA synthesis in primary mouse hepatocytes is associated with nuclear pro-transforming growth factor alpha and erbb-1 and is independent of c-jun. Carcinogenesis 2003, 24:835-841.

85. Adam RM, Danciu T, McLellan DL, Borer JG, Lin J, Zurakowski D, Weinstein MH, Rajjayabun PH, Mellon JK, Freeman MR: A nuclear form of the heparinbinding epidermal growth factor-like growth factor precursor is a feature of aggressive transitional cell carcinoma. Cancer Res 2003, 63:484-490.

86. Clevenger CV: Nuclear localization and function of polypeptide ligands and their receptors: a new paradigm for hormone specificity within the mammary gland? Breast Cancer Res 2003, 5:181-187.

87. Kimura H: Schwannoma-derived growth factor must be transported into the nucleus to exert its mitogenic activity. Proc Natl Acad Sci U S A 1993, 90:2165-2169

88. Bao J, Wolpowitz D, Role LW, Talmage DA: Back signaling by the Nrg-1 intracellular domain. J Cell Biol 2003, 161:1133-1141

89. Hanada N, Lo HW, Day CP, Pan Y, Nakajima Y, Hung MC: Co-regulation of B-Myb expression by E2F1 and EGF receptor. Mol Carcinog 2006, 45:10-17.

90. Lo HW, Hsu SC, Ali-Seyed M, Gunduz M, Xia W, Wei Y, Bartholomeusz G, Shih JY, Hung MC: Nuclear interaction of EGFR and STAT3 in the activation of the iNOS/NO pathway. Cancer Cell 2005, 7:575-589.

91. Hung LY, Tseng JT, Lee YC, Xia W, Wang YN, Wu ML, Chuang YH, Lai CH, Chang WC: Nuclear epidermal growth factor receptor (EGFR) interacts with signal transducer and activator of transcription 5 (STAT5) in activating Aurora-A gene expression. Nucleic Acids Res 2008, 36:4337-4351.

92. Huo L, Wang YN, Xia W, Hsu SC, Lai CC, Li LY, Chang WC, Wang Y, Hsu MC, $\mathrm{Yu} Y \mathrm{~L}$, et al: RNA helicase A is a DNA-binding partner for EGFR-mediated transcriptional activation in the nucleus. Proc Natl Acad Sci U S A 2010, 107:16125-16130.

93. Huang WC, Hung MC: Induction of Akt activity by chemotherapy confers acquired resistance. J Formos Med Assoc 2009, 108:180-194.

94. Williams CC, Allison JG, Vidal GA, Burow ME, Beckman BS, Marrero L, Jones FE: The ERBB4/HER4 receptor tyrosine kinase regulates gene expression by functioning as a STAT5A nuclear chaperone. J Cell Biol 2004, 167:469-478.

95. Hu S, Xie Z, Onishi A, Yu X, Jiang L, Lin J, Rho HS, Woodard C, Wang H, Jeong JS, et al: Profiling the human protein-DNA interactome reveals ERK2 as a transcriptional repressor of interferon signaling. Cell 2009, 139:610-622.

96. Tan M, Jing T, Lan KH, Neal CL, Li P, Lee S, Fang D, Nagata Y, Liu J, Arlinghaus $\mathrm{R}$, et al: Phosphorylation on tyrosine-15 of p34(Cdc2) by ErbB2 inhibits p34(Cdc2) activation and is involved in resistance to taxolinduced apoptosis. Mol Cell 2002, 9:993-1004.

97. Sorkin A, von Zastrow M: Endocytosis and signalling: intertwining molecular networks. Nat Rev Mol Cell Biol 2009, 10:609-622.

98. Doherty GJ, McMahon HT: Mechanisms of endocytosis. Annu Rev Biochem 2009, 78:857-902.

99. Johannes $L$, Popoff $V$ : Tracing the retrograde route in protein trafficking. Cell 2008, 135:1175-1187.

100. Spooner RA, Smith DC, Easton AJ, Roberts LM, Lord JM: Retrograde transport pathways utilised by viruses and protein toxins. Virol J 2006, $3: 26$.

101. Hsu WW, Lee SY, Yang JS: The evolving understanding of COPI vesicle formation. Nat Rev Mol Cell Biol 2009, 10:360-364.

102. Lee MC, Miller EA, Goldberg J, Orci L, Schekman R: Bi-directional protein transport between the ER and Golgi. Annu Rev Cell Dev Biol 2004, 20:87-123.

103. Cai H, Reinisch K, Ferro-Novick S: Coats, tethers, Rabs, and SNAREs work together to mediate the intracellular destination of a transport vesicle. Dev Cell 2007, 12:671-682.
104. Yang JS, Valente C, Polishchuk RS, Turacchio G, Layre E, Moody DB, Leslie CC, Gelb MH, Brown WJ, Corda D, et al: COPI acts in both vesicular and tubular transport. Nat Cell Biol 2011, 13:996-1003.

105. Boerner $\mathrm{JL}$, Demory ML, Silva C, Parsons SJ: Phosphorylation of Y845 on the epidermal growth factor receptor mediates binding to the mitochondrial protein cytochrome c oxidase subunit II. Mol Cell Biol 2004 , 24:7059-7071

106. Demory ML, Boerner JL, Davidson R, Faust W, Miyake T, Lee I, Huttemann M, Douglas R, Haddad G, Parsons SJ: Epidermal growth factor receptor translocation to the mitochondria: regulation and effect. J Biol Chem 2009, 284:36592-36604.

107. Cao X, Zhu H, Ali-Osman F, Lo HW: EGFR and EGFRvill undergo stress- and EGFR kinase inhibitor-induced mitochondrial translocalization: a potential mechanism of EGFR-driven antagonism of apoptosis. Mol Cancer 2011 10:26.

108. Dreier A, Barth S, Goswami A, Weis J: Cetuximab induces mitochondrial translocalization of EGFRvIll, but not EGFR: involvement of mitochondria in tumor drug resistance? Tumour Biol 2012, 33:85-94.

109. Hsu SC, Hung MC: Characterization of a novel tripartite nuclear localization sequence in the EGFR family. J Biol Chem 2007, 282:1043210440.

110. Giri DK, Ali-Seyed M, Li LY, Lee DF, Ling P, Bartholomeusz G, Wang SC, Hung MC: Endosomal transport of ErbB-2: mechanism for nuclear entry of the cell surface receptor. Mol Cell Biol 2005, 25:11005-11018.

111. Lo HW, Ali-Seyed M, Wu Y, Bartholomeusz G, Hsu SC, Hung MC: Nuclearcytoplasmic transport of EGFR involves receptor endocytosis, importin beta1 and CRM1. J Cell Biochem 2006, 98:1570-1583.

112. Wang ZH, Tian XX, Cheng Y, Yam GH, Ng HK, Ding MX, Chew-Cheng SB, Chew EC: Association of EGFR gene fragments with nuclear matrices in glioblastoma cell lines. Anticancer Res 1998, 18:4329-4332.

113. Klein C, Gensburger C, Freyermuth S, Nair BC, Labourdette G, Malviya AN: A $120 \mathrm{kDa}$ nuclear phospholipase Cgamma1 protein fragment is stimulated in vivo by EGF signal phosphorylating nuclear membrane EGFR. Biochemistry 2004, 43:15873-15883.

114. Progida C, Cogli L, Piro F, De Luca A, Bakke O, Bucci C: Rab7b controls trafficking from endosomes to the TGN. J Cell Sci 2010, 123:1480-1491.

115. Dunham-Ems SM, Pudavar HE, Myers JM, Maher PA, Prasad PN, Stachowiak MK: Factors controlling fibroblast growth factor receptor-1's cytoplasmic trafficking and its regulation as revealed by FRAP analysis. Mol Biol Cell 2006, 17:2223-2235.

116. Stachowiak MK, Maher PA, Stachowiak EK: Integrative nuclear signaling in cell development-a role for FGF receptor-1. DNA Cell Biol 2007, 26:811-826.

117. Reilly JF, Maher PA: Importin beta-mediated nuclear import of fibroblast growth factor receptor: role in cell proliferation. J Cell Biol 2001 152:1307-1312.

doi:10.1186/2045-3701-2-13

Cite this article as: Wang and Hung: Nuclear functions and subcellular trafficking mechanisms of the epidermal growth factor receptor family. Cell \& Bioscience 2012 2:13.

\section{Submit your next manuscript to BioMed Central and take full advantage of:}

- Convenient online submission

- Thorough peer review

- No space constraints or color figure charges

- Immediate publication on acceptance

- Inclusion in PubMed, CAS, Scopus and Google Scholar

- Research which is freely available for redistribution 